CORRECTION

\title{
Correction: Differential effects of growth hormone and alfa calcidol on trabecular and cortical bones in hypophysectomized rats
}

Afshan A. Chaudhry, Mariano Castro-Magana, John F. Aloia, James K. Yeh and Maria Sarah Guevarra

Pediatric Research (2020) 87:970; https://doi.org/10.1038/s41390-019-0680-5

Correction to: Pediatric Research (2009) 65, 403-408 https://doi. org/10.1203/PDR.0b013e3181975f70 published online April 2009

Following publication, the authors realized that 'Maria Sarah Guevarra' was accidentally omitted from the author list. The authorship of the article should include 'Maria Sarah Guevarra', since she was involved in the larger project, of which the study was part. The author list for the article should therefore be considered to be as follows:

Afshan A. Chaudhry ${ }^{1}$, Mariano Castro-Magana ${ }^{1}$, John F. Aloia ${ }^{2}$, James K. Yeh ${ }^{2,3}$, and Maria Sarah Guevarra

1. Department of Pediatric Endocrinology, Winthrop University Hospital, Mineola, New York, USA

2. Department of Medicine, Winthrop University Hospital, Mineola, New York, USA

3. Metabolism Laboratory, Winthrop University Hospital, Mineola, New York, USA

4. Department of Pediatrics, Winthrop University Hospital, Mineola, New York, USA
In addition, the article failed to acknowledge the fact that it was part of a larger project, and that the other part of this project examined the synergistic effect of PTH and GH on bone formation in hypophysectomized rats. ${ }^{1}$

Furthermore, a number of minor omissions/errors were made throughout the article. The methods section omitted that the $\mathrm{HX}$ rats were 8 weeks of age at the time they were assigned into groups. In Table 2, the unit for the trabecular number was misstated as '\#'. The correct unit is ' $\# / \mathrm{mm}^{\prime}$ '. The footnotes of tables 1-3 also omitted that part of the data for the 'INTACT', 'HX', and ' $\mathrm{HX}+\mathrm{GH}^{\prime}$ groups had also been used in the study by Guevarra et al., ${ }^{1}$ which was under review at the time.

The authors would like to apologize for these errors, and any inconvenience they may have caused. This has not been corrected in the PDF or HTML versions of the article.

\section{REFERENCES}

1. Guevarra, M. S., Yeh, J. K., Castro Magana, M. \& Aloia J. F. Synergistic effect of parathyroid hormone and growth hormone on trabecular and cortical bone formation in hypophysectomized rats. Horm. Res. Paediatr. 73, 248-257 (2010). 